\title{
Remote Wind-Driven Overturning in the Absence of the Drake Passage Effect
}

\author{
BARRY A. KLINGER \\ George Mason University, Fairfax, Virginia, and Center for Ocean-Land-Atmosphere Studies, Calverton, Maryland
}

SYBREN DRIJFHOUT

Royal Netherlands Meteorological Institute, De Bilt, Netherlands

JOCHEM MAROTZKE

Max Planck Institute for Meteorology, Hamburg, Germany

JEFFERY R. SCOTT

Massachusetts Institute of Technology, Cambridge, Massachusetts

(Manuscript received 1 August 2002, in final form 15 December 2003)

\begin{abstract}
Zonal wind stress over the Southern Ocean may be responsible for a significant fraction of the meridional overturning associated with North Atlantic Deep Water. Numerical experiments by Tsujino and Suginohara imply that the zonal periodicity of the Southern Ocean is not necessary for midlatitude westerly winds to drive strong remote meridional overturning. Here, idealized numerical experiments examine the importance of zonal periodicity and other factors in setting the sensitivity of this overturning to the wind stress. These experiments support the conclusion that the wind can drive remote overturning in the absence of zonal periodicity. However, making the subpolar ocean zonally periodic roughly doubles the strength of the overturning induced by the wind there. Tsujino and Suginohara's experiments are especially sensitive to wind stress because their basin has a relatively small meridional range, which increases the Ekman transport associated with the wind stress. Depending on the stratification in the wind-forcing region, the heating associated with the westerly winds can occur almost exclusively near the surface or deeper in the thermocline as well. Subsurface cooling in the wind-forcing region reduces the remote effects and can occur through both vertical or horizontal diffusion. A scale analysis of the heat budget suggests that sufficiently strong subpolar westerlies produce remote overturning because there is no way for local cooling to balance wind-induced surface heating. Tsujino and Suginohara suggested that wind increases the overturning by enhancing the mixing-driven thermohaline circulation. However, an increase in thermohaline circulation is associated with increased conversion of turbulent kinetic energy to potential energy. This increase in the energy conversion is absent in the wind-driven case, indicating an important qualitative difference between mixing-driven thermohaline overturning and remote wind-driven overturning.
\end{abstract}

\section{Introduction}

Toggweiler and Samuels (1995) showed that increasing the zonal wind stress south of $30^{\circ} \mathrm{S}$ in a global numerical ocean model increases the deep meridional overturning circulation associated with North Atlantic Deep Water (NADW). Their explanation of this influence focuses on the role of Ekman transport in the Southern Ocean. Net meridional geostrophic transport is impossible in zonally periodic regions, such as the top of the Southern Ocean, thus inhibiting the southward

Corresponding author address: Dr. Barry A. Klinger, Center for Ocean-Land-Atmosphere Studies, Suite 302, 4041 Powder Mill Rd., Calverton, MD 20705-3106.

E-mail: klinger@cola.iges.org flow needed to balance the northward Ekman transport. Much of the flow therefore occurs at deeper levels, where undersea ridges eliminate the zonal periodicity. It is difficult for water in the surface Ekman layer to sink locally to this great depth, which would entail very strong subsurface cooling along such a path. Instead much of the water takes a much longer path to the northern North Atlantic, which entails enough surface cooling for the water to sink to great depth as part of NADW. They call this behavior the "Drake Passage Effect" because the region of zonal periodicity in the Southern Ocean is in the latitude range of the Drake Passage between South America and the Antarctic Peninsula.

In contrast, Tsujino and Suginohara (1999, henceforth TsuSu) conducted numerical experiments in a closed basin in which adding wind to one hemisphere enhances 
the deep thermohaline cell across the entire basin. Their experiments implied that the behavior attributed to the Drake Passage effect can occur without any Drake Passage. To further study the role of the Southern Ocean, Klinger et al. (2003, henceforth KDMS), conducted numerical experiments in an idealized Atlantic basin in which the Southern Ocean consists of a "channel" region of zonal periodicity near the southern boundary. They found that wind stress perturbations in the channel, just north of the channel, and in the northern hemisphere, can all drive basin-scale perturbations to the meridional overturning. However, wind perturbations outside the channel are associated with shallower and weaker overturning anomalies than are wind perturbations inside the channel. Cox (1989) and Vallis (2000) also looked at the interaction of basin geometry and overturning but did not specifically address the sensitivity to wind stress.

TsuSu and KDMS have similar basin width $\left(60^{\circ}\right)$ and

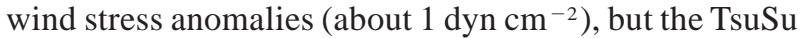
wind anomalies induce much stronger overturning anomalies: about $5 \mathrm{~Sv}\left(\mathrm{~Sv} \equiv 10^{6} \mathrm{~m}^{3} \mathrm{~s}^{-1}\right)$ crossing the equator as compared with the KDMS results of about $3 \mathrm{~Sv}$ cross-equatorial flow driven by wind anomalies in the channel and about $1 \mathrm{~Sv}$ driven by wind anomalies elsewhere. There is also the qualitative difference that in the TsuSu experiments the wind induces an overturning change over the entire water column, while in the KDMS experiments wind perturbations outside the channel are confined to relatively shallow depths.

These discrepancies are interesting for two reasons. One concerns the relative importance of the zonal periodicity in determining the impact of subpolar winds on overturning. The KDMS results imply that in the real world, variations in the subpolar winds of the Northern Hemisphere, for instance, are less significant for the circulation than variations over the Southern Ocean (though they show a fairly strong influence on heat transport). The TsuSu results, on the other hand, imply that Northern Hemisphere variations can be of first-order significance. The other reason is that the differences between TsuSu and KDMS raise broader dynamical questions: if the Southern Ocean does not cause the basinwide overturning to be sensitive to the wind, what does? In general, what factors control the sensitivity?

There are several differences between the TsuSu experiments and the KDMS experiments. We conduct a systematic analysis of differences between the two series of experiments and conduct numerical experiments to isolate and explain the differences. We also investigate the influence of other parameters such as horizontal diffusivity, which is important in the channel case (Gnanadesikan 1999; KDMS); wind perturbation amplitude; and the hemisphere in which the wind is applied.

In meridional overturning such as the NADW cells, water parcels generally cool in some regions and warm in others. In the classical thermohaline overturning cell, warming extends deep below the surface due to vertical diffusion. In Toggweiler and Samuels's conception, enhanced warming associated with wind stress occurs near the surface due to northward surface Ekman transport in the Southern Ocean (which forces water to warm as it flows to warmer latitudes). TsuSu analyze the temperature equation for their numerical experiments and argue that the heating occurs because the wind deforms the thermocline in such a way as to enhance diffusion over a region reaching down several hundred meters. They argue that this deep diffusion generates a basinscale thermohaline circulation just as an isolated region of enhanced mixing can drive a basin-scale circulation (Scott and Marotzke 2002). However, their thermodynamical analysis is performed on experiments with essentially no sea surface temperature (SST) gradient in the latitudes of the wind forcing so that Ekman transport cannot directly produce heating. In more realistic cases, does the wind-induced heating occur because of surface Ekman transport, subsurface diffusivity, or both? We analyze the temperature equation in order to identify the geography and cause of wind-driven heating in several cases with a meridional SST gradient.

As we shall see, wind perturbations can induce complicated patterns of subsurface heating and cooling. For motion to be driven by density differences only, as a heat engine, on average the heating must occur at greater pressure (greater depth) than the cooling (Sandstrom 1908). For a pure "buoyancy driven" or "thermohaline" oceanic circulation this occurs because turbulent kinetic energy (parameterized in the numerical models as vertical temperature diffusion) is converted to potential energy (see Huang 1998, 1999). TsuSu assert that the increase in meridional overturning associated with wind stress is due to the wind's indirect effect of increasing diffusion. This implies that the wind strengthens the potential energy conversion term. Toggweiler and Samuels (1998) used energetic arguments to highlight the different roles of wind in a single basin and in a global model. Here, we will measure the rate at which potential energy is generated by vertical diffusion to test the hypothesis that the rate increases when wind stress strengthens the meridional overturning.

Hasumi and Suginohara (1999) argue that the presence of the basinwide overturning follows from the wind-induced surface heat flux: heating in the hemisphere with a wind perturbation must be balanced by cooling in the other hemisphere, leading to a large-scale overturning. This explanation is plausible but incomplete since we cannot in general say a priori what the surface heat flux should be. For instance, one could imagine the wind inducing both positive and negative heat fluxes in the same hemisphere so that no basinwide overturning is required. We strengthen Hasumi and Suginohara's argument by using scaling arguments to show that that equatorward Ekman transport should induce net local heating that would need to be balanced by net cooling elsewhere. 
TABLE 1. Summary of experiments, normalized overturning volume transport anomaly. The normalized transport represents the meridional volume transport anomaly, relative to the appropriate No-Wind experiment, normalized by peak Ekman transport of westerly winds. "Surface" refers to the surface value at the latitude of peak Ekman transport used for normalization, and "equator" refers to cross-equatorial transport of the anomalous deep cell. Peak Ekman transport is 9.6 Sv for experiment TsuSu/Full-Wind, 5.8 Sv for Full-Wind in the long-basin experiments, and $5.2 \mathrm{~Sv}$ for Westerlies winds. Volume transports are based on zonal averages of velocity along constant $z$ $(\phi)$ and constant $T\left(\phi_{T}\right)$.

\begin{tabular}{|c|c|c|c|c|}
\hline \multirow[b]{2}{*}{ Run name } & \multicolumn{2}{|c|}{$\phi$} & \multicolumn{2}{|c|}{$\phi_{T}$} \\
\hline & Surface & Equator & Surface & Equator \\
\hline \multicolumn{5}{|c|}{ Short-basin experiments } \\
\hline TsuSu/No-Wind & & & & \\
\hline TsuSu/Full-Wind & 0.88 & 0.56 & 0.69 & 0.65 \\
\hline $\begin{array}{l}\text { Layer/No-Wind } \\
\text { Layer/Full-Wind }\end{array}$ & 0.41 & 0.32 & 0.40 & 0.39 \\
\hline \multicolumn{5}{|c|}{ Long-basin experiments } \\
\hline \multicolumn{5}{|c|}{ Very asymmetric SST } \\
\hline $\begin{array}{l}\text { TsuSu64/No-Wind } \\
\text { TsuSu64/Full-Wind } \\
\text { Very-Asym/No-Wind }\end{array}$ & 0.86 & 0.48 & 0.72 & 0.59 \\
\hline Very-Asym/Full-Wind & 0.86 & 0.41 & 0.66 & 0.53 \\
\hline Very-Asym/2Wind & 0.91 & 0.54 & 0.65 & 0.65 \\
\hline \multicolumn{5}{|l|}{ Slightly asymmetric SST } \\
\hline $\begin{array}{l}\text { No-Wind } \\
\text { Full-Wind }\end{array}$ & 0.84 & 0.34 & 0.62 & 0.43 \\
\hline SH-Westerlies & 0.90 & 0.27 & 0.65 & 0.35 \\
\hline NH-Westerlies & 0.92 & 0.29 & 0.52 & 0.21 \\
\hline Lo- $\kappa_{H} / \mathrm{No}-$ Wind & & & & \\
\hline Lo- $\kappa_{H} /$ Westerlies & 0.87 & 0.19 & 0.63 & 0.27 \\
\hline Channel/No-Wind & & & & \\
\hline Channel/Westerlies & 0.98 & 0.56 & 0.86 & 0.65 \\
\hline
\end{tabular}

In the real world, the Atlantic and Pacific Oceans are connected in the north (via the Arctic Ocean) as well as in the south. Nof $(2000,2002)$ present an intriguing theory that the two connections strongly constrain the overturning circulation. To our knowledge, this theory has not been tested with a model that includes vertical structure or thermodynamics. However, it raises the possibility that there could be qualitative differences in the behavior of the system when the northern geography is taken into account.

\section{Numerical configurations}

For almost all of the experiments, we use the Geophysical Fluid Dynamics Laboratory Modular Ocean Model (MOM) version 2.2 (Pacanowski 1996), a primitive equation model in spherical coordinates in the horizontal and constant-depth coordinates in the vertical. As in KDMS, a longer time step is used in the temperature equation than in the momentum equations (Bryan 1984), and the convergence to a steady state is hastened by exponential extrapolation of zonal averaged temperature (Klinger 2000). Each experiment is integrated until meridional overturning change is small
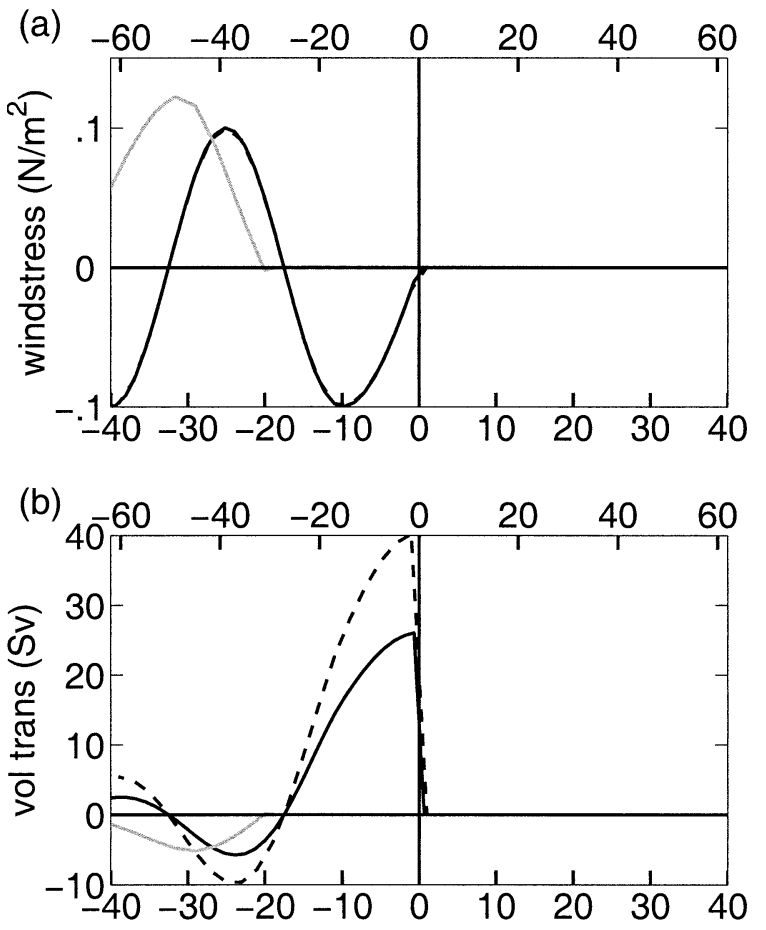

FIG. 1. Wind profiles for the TsuSu case (black) and for the Westerlies case (gray). Figures are shown for a $40^{\circ}$ basin (bottom scale, dashed curve) and for $64^{\circ}$ basin (top scale, solid curves). (a) Zonal wind stress and (b) Ekman volume transport.

(about $0.01 \mathrm{~Sv}$ century ${ }^{-1}$ ) and decreasing; typically, this is around $2000 \mathrm{yr}$.

All experiments are summarized in Table 1. We start by reproducing two experiments of TsuSu to make sure numerical issues are not responsible for any of the differences. In their experiments, the sinking that corresponds to NADW formation occurs in the southern hemisphere; here we reflect surface forcing about the equator so that NADW formation occurs in our basin's northern hemisphere. Like TsuSu, we conduct the experiments in a basin that runs from $40^{\circ} \mathrm{S}$ to $40^{\circ} \mathrm{N}$, is $60^{\circ}$ wide, $4000 \mathrm{~m}$ deep, with $2^{\circ}$ resolution in latitude and longitude, and with 32 vertical levels with resolution ranging from $50 \mathrm{~m}$ at the top to $200 \mathrm{~m}$ near the bottom. We duplicate their vertical and horizontal diffusion of $\kappa_{V}=0.3 \mathrm{~cm}^{2} \mathrm{~s}^{-1}$ and $\kappa_{H}=1000 \times 10^{4} \mathrm{~cm}^{2} \mathrm{~s}^{-1}$ and vertical and horizontal viscosity of $\nu_{V}=1 \mathrm{~cm}^{2} \mathrm{~s}^{-1}$ and $\nu_{H}=8 \times 10^{8} \mathrm{~cm}^{2} \mathrm{~s}^{-1}$, and we employ a linear equation of state. As in their experiments, the top-level density is restored (with a 60-day time scale) to a profile that varies linearly with latitude $\phi$ within each hemisphere and which has a range of $4 \mathrm{~kg} \mathrm{~m}^{-3}$ in the hemisphere where deep water is formed and $3 \mathrm{~kg} \mathrm{~m}^{-3}$ in the other hemisphere. One experiment, TsuSu/No-Wind, has no wind stress. In the other experiment, TsuSu/Full-Wind, we approximately reproduce the wind stress in TsuSu's Fig. 2b with alternating easterly, westerly, and easterly winds in the southern hemisphere (Fig. 1a) given by the following Full Wind profile: 


$$
\tau=\sin \left(\frac{\pi \phi}{\phi_{A}}\right) \quad\left(0>\phi>-\frac{\phi_{A}}{2}\right)
$$

and

$$
\tau=\cos \left[\pi \frac{\phi-(5 / 4) \phi_{A}}{(3 / 4) \phi_{A}}\right] \quad\left(\phi<-\frac{\phi_{A}}{2}\right),
$$

where $\phi_{A}=20^{\circ}$.

This configuration differs from that of KDMS in several ways besides the absence of a channel region. Differences in mixing coefficients, resolution, and bottom depth (4500 $\mathrm{m}$ in KDMS) may all make incremental changes, though KDMS showed that the wind-induced overturning is not sensitive to $\kappa_{V}$. KDMS used a nonlinear equation of state with forcing in both temperature and salinity. The wind stress and the profile to which surface density is restored are different; we address these below. A major difference, which may seem trivial at first, is the latitudinal extent of the basin; in KDMS the polar boundaries are at $68^{\circ} \mathrm{S}$ and $64^{\circ} \mathrm{N}$. This is an important difference because the Ekman volume transport is proportional to basin width divided by the Coriolis parameter and, hence, proportional to $\cos (\phi) /$ $\sin (\phi)$. Therefore, at least part of the greater TsuSu sensitivity to wind may be due to the Ekman transport being greater when "subpolar" winds are at a lower latitude (Fig. 1b). We test this with experiments TsuSu64/NoWind and TsuSu64/Full-Wind, in which the basin extends from $64^{\circ} \mathrm{S}$ to $64^{\circ} \mathrm{N}$, with forcing profiles "stretched" to fill the longer basin $\left(\phi_{A}=31^{\circ}\right.$; see Figs. la,b).

Additional closed-basin experiments isolate other differences between the TsuSu experiments and the KDMS experiments. Experiments Very-Asym/No-Wind and Very-Asym/Full-Wind repeat the TsuSu64 experiments with a depth of $4500 \mathrm{~m}, 16$ vertical levels, and horizontal viscosity of $\nu_{H}=2.5 \times 10^{9} \mathrm{~cm}^{2} \mathrm{~s}^{-1}$, as in KDMS. Further experiments, using these parameter values, explore how the wind-driven overturning anomaly depends on the surface density forcing, wind stress profile, presence of a zonal channel, and lateral mixing parameterization. The configuration details for each of these experiments are described in the experimental results section (section 3 ).

\section{Comparison of numerical experiments}

\section{a. Sensitivity to basin length}

First we reproduce the TsuSu experiments, comparing TsuSu/Full-Wind with TsuSu/No-Wind (see section 2). The difference in meridional overturning $\Phi$ between the two cases is similar to the TsuSu result. An overturning cell fills the basin, with peak transport of $7 \mathrm{~Sv}$ and with about 5.4 Sv crossing the equator; both figures are within $0.5 \mathrm{~Sv}$ of the values inferred from TsuSu's Fig. 10. We attribute small differences between our experiments and theirs to the different numerical schemes.
When the same wind and density forcing is "stretched" to force the flow in a longer basin, the TsuSu64/Full-Wind, TsuSu64/No-Wind, and difference overturning patterns are similar to the original $40^{\circ}$ basin (TsuSu Fig. 10). The deep overturning anomaly weakens, with cross-equatorial transport of $2.8 \mathrm{~Sv}$, or $52 \%$ of the $40^{\circ}$ basin. Can we attribute this reduction entirely to the reduced Ekman transport associated with higher latitudes? The reduction in Ekman volume transport is given by $\tan (\phi) / \tan (1.55 \phi)$, where the factor $1.55=$ $31 / 20$ represents the ratio of latitude ranges. This reduction is about 0.59 at the peak northward Ekman transport (at $37^{\circ} \mathrm{N}$ in the longer basin). If reduction in the overturning anomaly is due only to this reduction in Ekman transport, then these results imply that the overturning anomaly is not linearly proportional to Ekman transport. We will return to this point shortly.

Repeating the same experiment except with the KDMS resolution and $\nu_{H}$ (Very-Asym/Full-Wind and Very-Asym/No-Wind; see section 2), the overturning anomaly weakens somewhat with cross-equatorial transport decreasing by $14 \%$ to $2.4 \mathrm{~Sv}$. Most of the change occurs because the deep overturning in the no-wind experiment increases. As with the TsuSu64 experiments above, our overturning patterns (Fig. 2, left panels) are similar to those in TsuSu (their Fig. 10). All following experiments will also be conducted with the same configuration except for forcing changes.

When we impose the same wind stress pattern with double the amplitude (Very-Asym/2Wind), the crossequatorial transport increases by a factor of 2.6 to 6.3 Sv. This confirms that the overturning anomaly is indeed a nonlinear function of Ekman transport. The subpolar meridional volume transport in the top layer of the model, dominated by Ekman transport, is approximately proportional to the wind stress. This implies that Sverdrup transport and western boundary current transport nearly compensate in the model. However, the fraction of this overturning that recirculates within a local, shallow cell (Fig. 2c) and the fraction that takes the deep, basinwide path is different in the two cases.

\section{b. Sensitivity to surface density asymmetry}

Here we discuss the sensitivity of the wind-driven anomalies to characteristics of the basic state as determined by the density forcing. The experiments in the previous subsection are forced by the same very asymmetric surface temperature profile (stretched in latitude) as in TsuSu. Other experiments have a temperature profile inspired by the KDMS experiments (their Fig. 1). The KDMS density profile is more symmetric about the equator than is the TsuSu profile. We denote surface density differences by $\Delta \rho_{N}$ for the northern hemisphere range and $\Delta \rho_{p}$ for northern hemisphere maximum minus southern hemisphere maximum. This profile has $\Delta \rho_{p} /$ $\Delta \rho_{N}=0.04$ as compared with $\Delta \rho_{p} / \Delta \rho_{N}=0.25$ for the TsuSu profile. As discussed in Klinger and Marotzke 
(a)

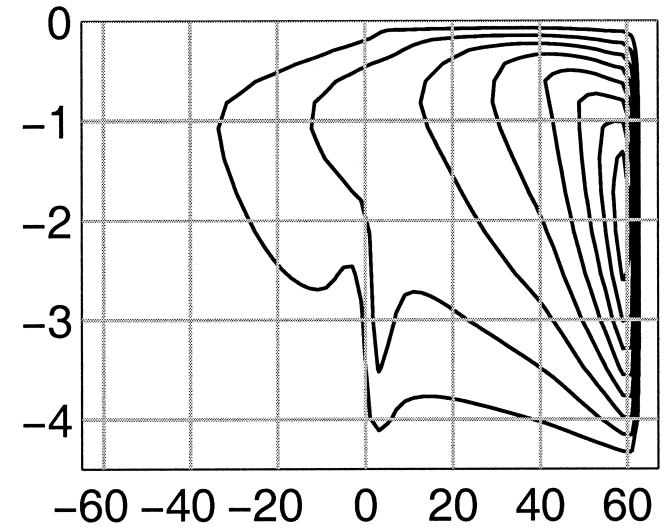

(b)

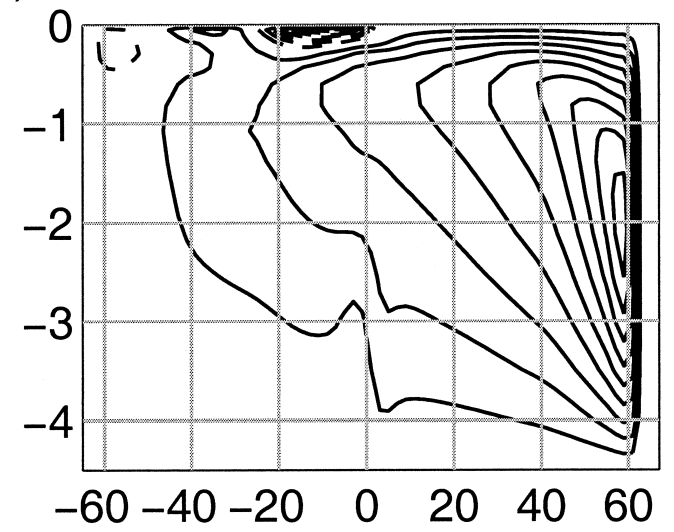

(c)

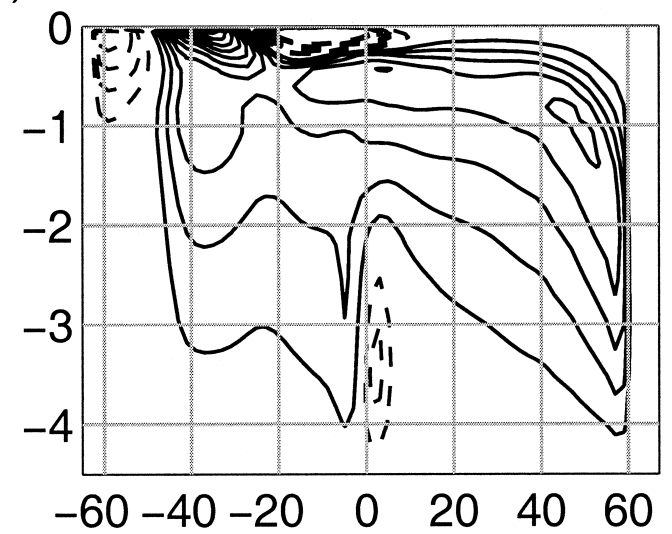

(d)

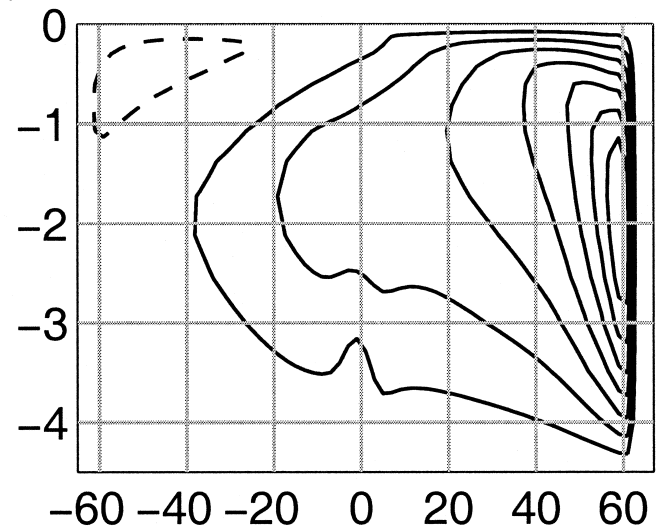

(e)

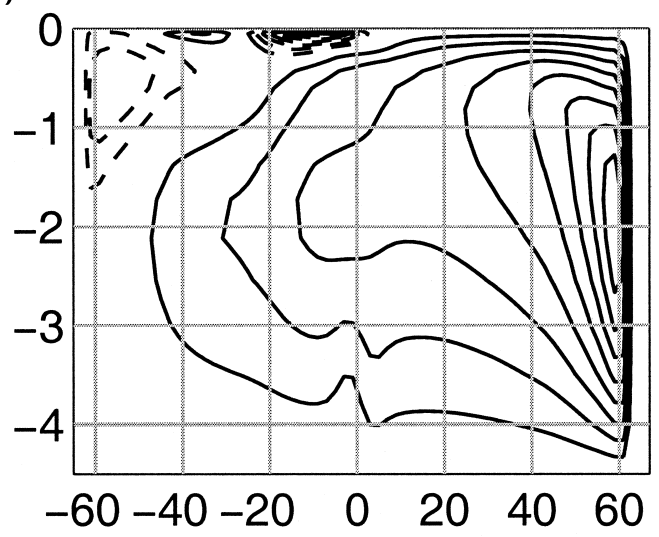

(f)

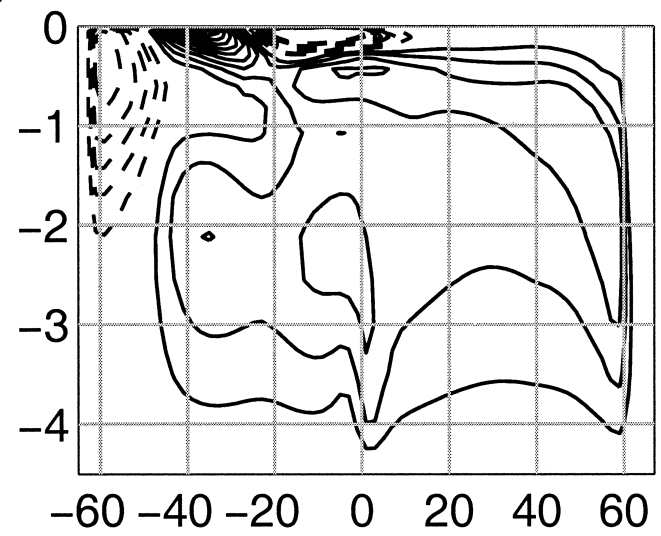

FIG. 2. Meridional overturning streamfunction $\Phi(\phi, z)$ for closed basin experiments, (top) no-wind, (middle) wind-forced, and (bottom) wind-forced minus no-wind for equatorially (left) very symmetric and (right) slightly symmetric surface density forcing. For all panels, solid lines denote northern-sinking cells and dashed lines denote southern-sinking cells; zero contours are omitted. Contour interval is $0.5 \mathrm{~Sv}$ for difference fields $(|\Phi|$ contours $>5 \mathrm{~Sv}$ not shown) and $2 \mathrm{~Sv}$ for all others.

(1999), both stratification and overturning profiles are quite sensitive to small departures from equatorial symmetry in the surface density. To reproduce the effect of having more equatorially symmetric density forcing we run experiments with slightly asymmetric SST, which also have $\Delta \rho_{N}=4 \mathrm{~kg} \mathrm{~m}^{-3}$ but with $\Delta \rho_{p} / \Delta \rho_{N}=0.0674$.
This configuration is used with no wind forcing (NoWind) and with the stretched wind (Full-Wind).

In the No-Wind cases, the asymmetric surface density creates a "dominant" overturning cell that supplies deep water to the entire basin and a shallower "subordinate" cell, confined to the upper part of the subordinate hemi- 
sphere, that has the lighter surface density. As expected (Klinger and Marotzke 1999), the smaller density asymmetry of the No-Wind experiment produces a deeper mixed layer in the subordinate hemisphere and a deeper and stronger subordinate cell than in the Very-Asym/ No-Wind experiment (Fig. 2, top panels).

For both degrees of asymmetry, the wind-induced upwelling in the subordinate hemisphere "feeds" (strengthens) both the dominant and the subordinate cells (Fig. 2, middle panels). The more symmetric the no-wind state, the more the wind feeds the subordinate cell (Fig. 2, bottom panels). Similarly, the wind-induced change in the dominant cell is weaker by about $33 \%$ in Full-Wind (which has slightly asymmetric SST) than for Very-Asym/Full-Wind. It is interesting that relatively small changes in the base state can make relatively large changes in the response to the wind.

\section{c. Sensitivity to wind stress pattern and geometry}

TsuSu studied a closed basin driven by alternating bands of tropical easterlies, midlatitude westerlies, and polar easterlies (Fig. 1), and KDMS, Toggweiler and Samuels (1995), and others studied westerly winds in a basin with a channel (Fig. 1). Here we view the overturning driven by westerlies in the closed basin ( $\mathrm{SH}-$ Westerlies, same surface density restoring as No-Wind). The wind stress consists of westerlies (difference between the "strong wind" and "weak wind" cases in KDMS) between latitude $30^{\circ} \mathrm{S}$ and the southern boundary. The relatively simple wind pattern of this experiment simplifies our exploration of the role of other parameters (see below) and also simplifies our examination of the water mass transformations (see sections 4 and 5).

With the simplified wind forcing, the cells associated with the trades and high-latitude easterlies disappear, as expected (Fig. 3a). The remaining overturning cell is qualitatively similar to the westerlies-driven cell in the Full-Wind experiment (Figs. 2c,f). The peak northward Ekman transport is farther south and about $10 \%$ weaker than in the Full-Wind case, while the scaled basin-scale overturning is about $20 \%$ weaker (see Table 1 ).

In the KDMS experiments, the ocean response to a wind perturbation strongly depends on the hemisphere of the perturbation (cf. their Fig. 8, right panels, and Fig. 9, left panels). In those experiments, the southern hemisphere has the added feature of the channel. A northern hemisphere wind perturbation drives a shallower cell than does a southern-hemisphere perturbation. Here, we conduct experiment NH-Westerlies to see whether the response to a northern wind differs from the response to a southern wind when the only other asymmetry between hemispheres is due to the surface density forcing.

In a closed basin, the hemisphere of the wind forcing does make one dramatic difference: southern (subordinate) hemisphere wind stress drives a much deeper (a)

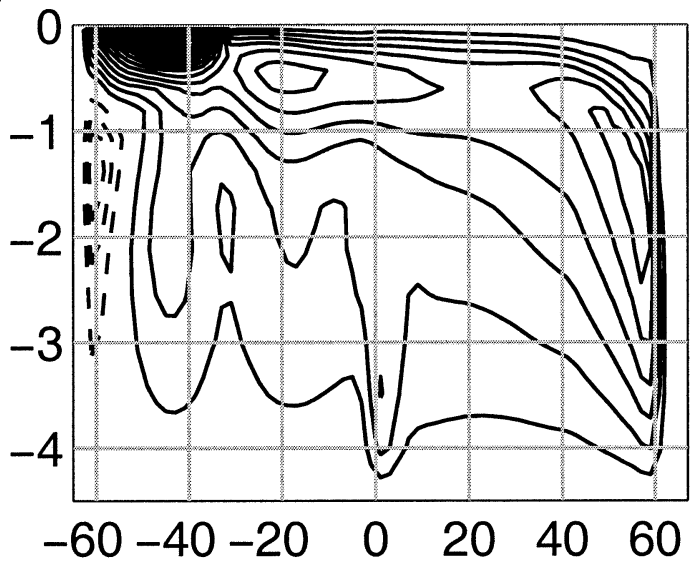

(b)

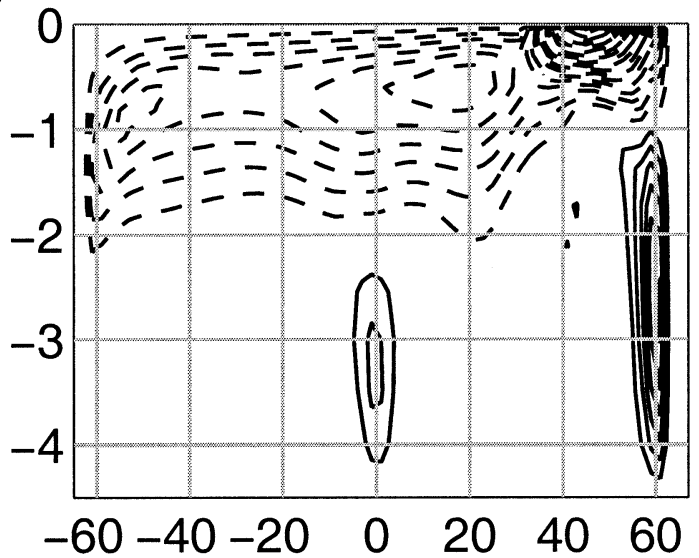

FIG. 3. Meridional overturning streamfunction anomaly (relative to No-Wind case) for westerlies wind forcing with wind in the (a) southern hemisphere and (b) northern hemisphere. Contour interval is $0.25 \mathrm{~Sv}$; line types are as in Fig. 2.

overturning than northern (dominant) hemisphere wind stress (Fig. 3). However, the magnitude of the overturning is similar: 1.4 Sv crossing the equator for northern hemisphere wind and 1.5 Sv for southern hemisphere wind.

It is somewhat counterintuitive that wind over the subordinate hemisphere drives a deeper overturning than wind over the dominant hemisphere. One might expect the opposite, with wind effects reaching more deeply for wind in the dominant hemisphere, where denser water is ventilated.

How important is the presence of a zonal channel in the wind-perturbation region? In KDMS, westerly winds over the southern ocean channel drive a 3.2-Sv transport anomaly across the equator, but comparison with the $\mathrm{SH}-$ Westerlies experiment described above is complicated by other differences between the experiments, such as surface density forcing, equation of state, and base wind forcing to be perturbed. Therefore we conducted experiments Channel/No-Wind and Channel/ 
Westerlies to repeat No-Wind and SH-Westerlies but with a zonally periodic channel from $50^{\circ}$ to $60^{\circ} \mathrm{S}$ and extending to a depth of $2545 \mathrm{~m}$ as in KDMS. Including the channel roughly doubles the strength of the basinscale overturning anomaly with $2.9 \mathrm{~Sv}$ of cross-equatorial transport, which is similar to the KDMS transport.

\section{d. Sensitivity to lateral diffusion}

In the preceding experiments, lateral mixing by mesoscale eddies is parameterized by horizontal diffusion, like the experiments in TsuSu and some of the experiments in KDMS. However, along-isopycnal diffusion of "thickness" (Gent and McWilliams 1990) may be a better parameterization. As a test that the results discussed here are not dependent on the eddy parameterization, we use the layer model described in KDMS to conduct Layer/No-Wind and Layer/Full-Wind to repeat the TsuSu/No-Wind and TsuSu/Full-Wind experiments.

In the layer model, the $\Phi$ anomaly overturning associated with Full winds (not shown) has a similar pattern to the corresponding level model experiments, but about one-half of the magnitude. This is true of the surface volume transport as well, where the peak volume transport at about $25^{\circ} \mathrm{N}$ is only one-half of the peak Ekman transport. The Layer/No-Wind overturning is also about one-half as strong as in TsuSu/No-Wind. Thus whether we normalize the cross-equatorial $\Phi$ anomaly with the No-Wind overturning or the surface volume transport, the normalized value is similar to that in the Level model. The difference in raw values of volume transport between the Layer and Level models is a function of the different numerics as well as the different parameterization of eddies (lateral thickness diffusion vs horizontal temperature diffusion).

Gnanadesikan (1999) showed that the basinwide overturning associated with wind over the Southern Ocean is given by the Southern Ocean northward Ekman transport minus a southward component associated with meridional thickness diffusion, so that increasing the thickness diffusivity $\kappa_{I}$ reduces the wind-driven component. KDMS found qualitatively similar sensitivity to horizontal diffusivity $\kappa_{H}$. To see if a closed basin has similar sensitivity to $\kappa_{H}$, experiments Lo- $\kappa_{H} /$ No-Wind and Lo- $\kappa_{H} /$ Westerlies repeat No-Wind and SH-Westerlies but with $\kappa_{H}$ reduced by a factor of 10 to $100 \times 10^{4}$ $\mathrm{cm}^{2} \mathrm{~s}^{-1}$.

The Lo- $\kappa_{H}$ experiments show the closed-basin flow to have a radically different sensitivity to $\kappa_{H}$ than the case with wind blowing in a zonally periodic region. The basinwide overturning anomaly driven by the westerlies is similar to the case with default $\kappa_{H}$; moreover it is somewhat smaller rather than greater in the case of low $\kappa_{H}$. In the case of the channel, horizontal diffusion is more important because meridional geostrophic flow is inhibited by the zonal periodicity of the domain. When the domain has eastern and western boundaries, geostrophic flow is allowed throughout the water column and other terms besides horizontal diffusion can-and apparently do-control the amount of overturning that leaves the wind stress region. The role of horizontal diffusion as well as the other terms in the temperature evolution equation will be discussed further in section 4 .

\section{e. Summary of comparison}

Table 1 summarizes the strengths of the overturning anomalies due to all the wind perturbations. The numbers are normalized by the peak Ekman transport $\Phi_{\mathrm{Ek}}$ of the westerly winds and show top-level volume transport at the latitude of $\Phi_{\mathrm{Ek}}$ as well as cross-equatorial transport. As expected, the surface volume transport anomaly is nearly as large as the Ekman transport, at least in the level model experiments. In all experiments, at least one-half of the anomalous surface volume transport recirculates locally and the remainder feeds a basinwide cell. Both the TsuSu experiment and the Channel/Westerlies experiment have a cross-equatorial volume transport anomaly of $0.56 \Phi_{\mathrm{Ek}}$. Replacing the channel with closed boundaries leads to a dramatic reduction in the equatorial flow to $0.29 \Phi_{\mathrm{Ek}}$. All other parameter changes have more modest influences. Thus if we start with the TsuSu experiments, lengthen the basin, reduce the vertical resolution (simultaneously raising $\nu_{H}$ ), and make the restoring SST less equatorially asymmetric, then each change reduces the equatorial flow anomaly; together they bring it down to $0.34 \Phi_{\mathrm{Ek}}$. Generally the fraction of $\Phi_{\mathrm{Ek}}$ crossing the equator increases with $\Phi_{\mathrm{Ek}}$.

\section{Modes of water mass transformation}

The numerical experiments discussed in the previous section have shown how the sensitivity of overturning to remote wind forcing varies with some key parameters governing the system. Here, we analyze the thermodynamic cycles of cooling and heating associated with the wind-driven overturning. As discussed in the introduction, TsuSu infers that the wind drives a basin-scale overturning by strengthening vertical diffusion (hence subsurface heating) beneath the wind. We examine this hypothesis for the experiments discussed above, using several techniques. First we look at the $T$-coordinate overturning (section $4 \mathrm{a}$ ), which produces a striking picture of where water transformation occurs (section 4b). We then analyze the advection-diffusion equation for temperature in order to locate more precisely the depth and mechanism of heating and cooling (section 4c). Last we relate the heating and cooling to the basin's energy budget (section $4 \mathrm{~d}$ ).

\section{a. Comparison of T-coordinate and z-coordinate overturning strength}

In order to view the overturning circulation in a way that makes heating and cooling more apparent, it is useful to consider the meridional volume transport defined 
(a)

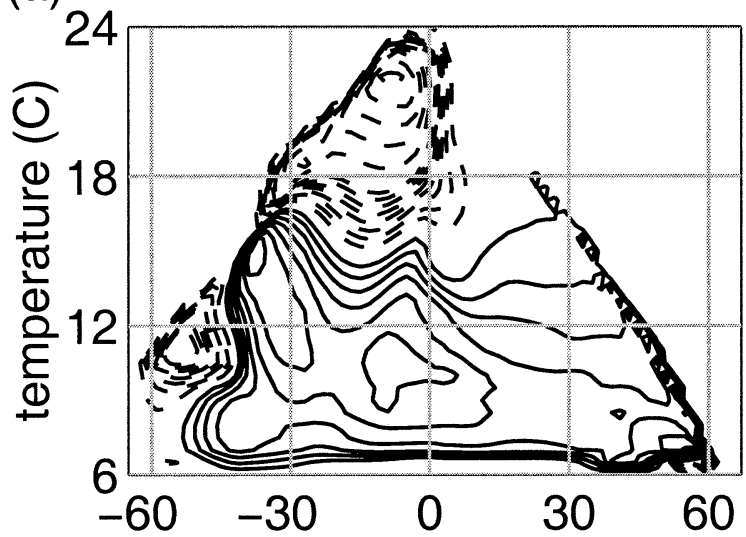

(c)

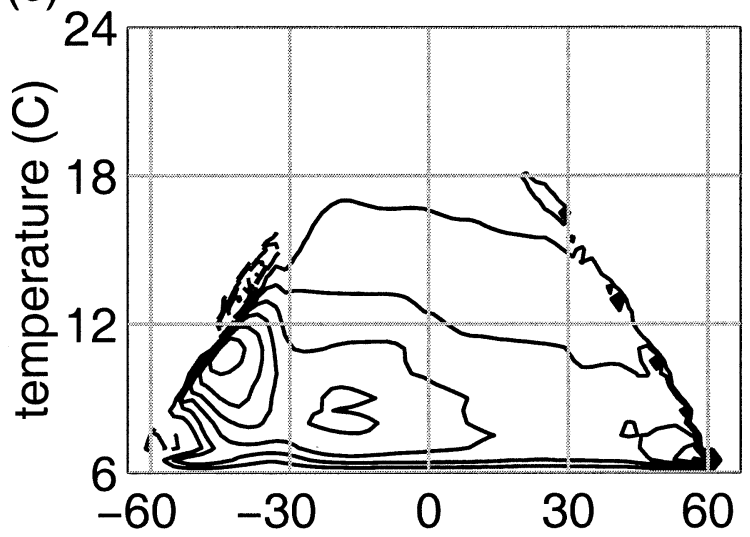

(b)

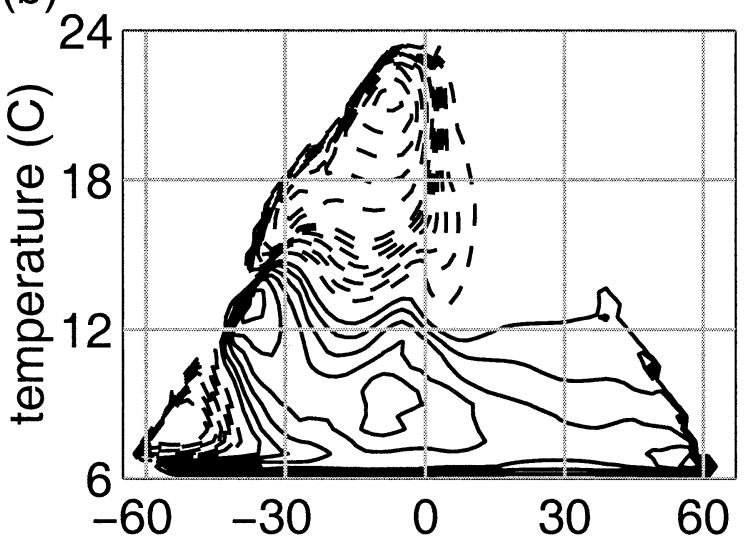

(d)

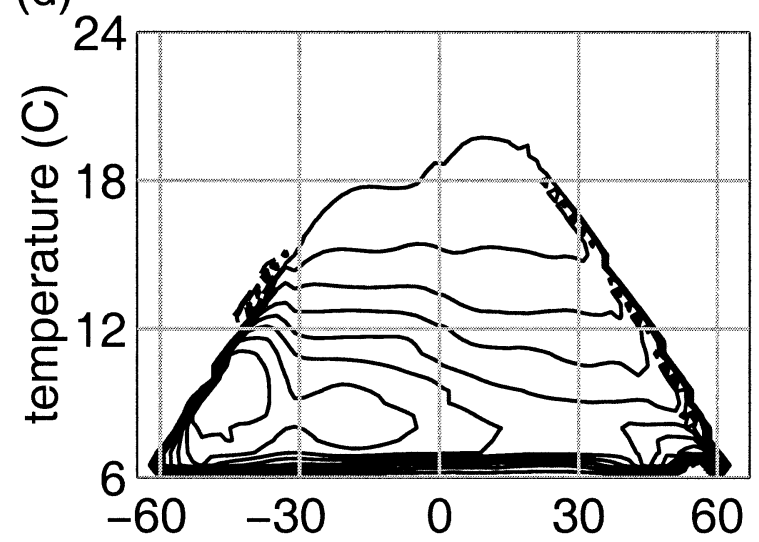

FIG. 4. Meridional overturning $\Phi_{T}$ showing differences between (a) Very-Asym/Full-Wind and Very-Asym/No-Wind, (b) Full-Wind and No-Wind, (c) SH-Westerlies and No-Wind, and (d) Channel/Westerlies and Channel/No-Wind. Contour interval is $0.5 \mathrm{~Sv}$ for magnitude up to $4 \mathrm{~Sv}$ and is $2 \mathrm{~Sv}$ for higher values. Line types as in Fig. 2.

by taking the zonal integral of meridional velocity at latitude $\phi$ and temperature $T$. The resulting streamfunction, $\Phi_{T}(\phi, T)$, shown in Fig. 4, displays "horizontal" streamlines when there is no net heating and cooling at a particular $(\phi, T)$, and is closely linked to the meridional heat transport (see, e.g., Klinger and Marotzke 2000). Before using $\Phi_{T}$ to illustrate the heating and cooling induced by the wind, we compare $\Phi_{T}$ anomalies with $\Phi$ anomalies.

The $\Phi_{T}$ anomalies are similar to the $\Phi$ anomalies, but there are also significant differences. Qualitative differences between the Ekman cells associated with the trade winds and the westerlies (for instance Figs. $2 \mathrm{f}$ and 4a) have been discussed by Klinger and Marotzke (2000). In the SH-Westerlies anomaly (Fig. 4c), there is a strong cell near $40^{\circ} \mathrm{S}$ in the warmest temperature ranges associated with the warm, southward-flowing western boundary current.

In all experiments, zonal temperature differences cause the peak normalized "surface" (warmest water) $\Phi_{T}$ to be substantially less than the surface $\Phi$ anomaly (see Table 1). This measure of volume transport also shows greater variability, relative to its average, than the corresponding surface $\Phi$ value (Table 1), which is not surprising since it is not as directly linked to the zonal average Ekman transport. Generally the response of the cross-equatorial $\Phi_{T}$ and $\Phi$ anomalies shows similar sensitivity to changes in external conditions. However, moving the westerlies from the southern hemisphere to the northern hemisphere does not significantly change the magnitude of the $z$-coordinate transport, but it does reduce the $T$-coordinate transport from $0.35 \Phi_{\mathrm{Ek}}$ to $0.21 \Phi_{\mathrm{Ek}}$ (Table $1, \Phi_{T}$ "equator" values).

\section{b. Surface and subsurface heating}

TsuSu emphasize the subsurface heating in their experiments. To what extent does the wind-driven temperature transformation occur via subsurface heating in our experiments?

The subsurface heating associated with this circulation can be inferred from the $\Phi_{T}$ anomaly for experiment Very-Asym/Full-Wind relative to Very-Asym/No-Wind (Fig. 4a). That figure shows a basinwide deep cell largely between about $6^{\circ}$ and $15^{\circ} \mathrm{C}$. The streamlines of this cell show intense "upwelling" (heating) in the vicinity 
of $40^{\circ} \mathrm{S}$. Some of this heating occurs in the warmest water at a given latitude, which is in contact with the surface, but much of it occurs at cooler temperatures. Strong restoring to zonally uniform temperatures makes the SST range at each latitude relatively narrow, so this cooler water is below the surface. In the case examined most closely by TsuSu, there is no meridional SST gradient in the wind-driven hemisphere so that the equatorward Ekman transport is not associated with any heating, leaving only the subsurface diffusion to provide the heating necessary for the wind-driven cell.

In the less asymmetric case (Full-Wind experiment relative to No-Wind), $\Phi_{T}$ has a similar pattern (Fig. 4b), but the streamlines undergo a smaller subsurface change in temperature in the upwelling region. Apparently this is merely because the surface is colder than the more asymmetric case, and the surface warming associated with Ekman transport is about the same. In the SHWesterlies experiment (relative to No-Wind), the more southern location of the westerlies means the surface water is even colder in that case, and the subsurface heating, at about $50^{\circ} \mathrm{S}$, is even less important (Fig. 4c). One might be tempted to deduce from this that the subsurface heating is necessary to drive the basinwide cell since in these cases the greater the subsurface heating, the stronger the cross-equatorial flow. However, the case with a periodic channel has a large basinwide overturning anomaly and almost no subsurface heating anomaly (Fig. 4d). This is consistent with the global model result of Döös and Webb (1994; see their Fig. 4.2).

\section{c. Heating depth and cooling mechanism}

The $\Phi_{T}$ figures imply that heating associated with the wind-driven cell can be supplied by either subsurface or surface processes. To look more carefully at the depth of the heating, we will consider the temperature evolution equation, which in steady state can be written

$$
\boldsymbol{\nabla} \cdot(\mathbf{u} T)=\kappa_{V} T_{z z}+\kappa_{H} \nabla_{H}^{2} T+C,
$$

where $\mathbf{u}$ is velocity, $\nabla_{H}^{2}$ represents the horizontal components of the Laplacian, and $C$ represents the heating and cooling caused by convective adjustment. We can refer to both left- and right hand sides of (2) as heating (positive values) or cooling (negative values). Equation (2) shows that the heating or cooling of a water parcel is due to vertical and horizontal diffusion and convection. It should be noted that, in the top level of the model, vertical diffusion is dominated by the surface heat flux, and so it is appropriate to associate subsurface heating with mixing and to associate heating in the top $50 \mathrm{~m}$ with direct surface forcing.

The zonal average value of $\boldsymbol{\nabla} \cdot(\mathbf{u} T)$ is a measure of the net heating and cooling of the water as it circulates. Here we examine the changes in heating and cooling driven by westerly winds in the subordinate hemisphere. In the No-Wind experiment, the pattern is what one might expect from the overturning streamfunction (Fig. $2 \mathrm{a})$, with heating where the water upwells through the thermocline and cooling where the water flows poleward in the mixed layer (Fig. 5a). In the SH-Westerlies run (Fig. 5b), there is strong surface warming south of $30^{\circ} \mathrm{S}$ due to the northward Ekman transport.

To see exactly what cooling and heating is due to the wind forcing, we examine the difference between the SH-Westerlies and No-Wind experiments (Fig. 5c). This shows that adding the wind causes heating near the surface and mostly cooling at depth south of $30^{\circ} \mathrm{S}$, unlike the case analyzed in TsuSu. The SH-Westerlies heating anomaly is largely confined to the top level of the model, which is $52 \mathrm{~m}$ thick. The subsurface warming at about $50^{\circ} \mathrm{S}$ in Fig. $4 \mathrm{c}$ is hardly visible in the constant-depth average. In the Full-Wind case (Fig. 5d), the heating anomaly in the high-latitude upwelling region extends downward several hundred meters, as in TsuSu, at about the same latitude as in Fig. 4b. The largest heating is at the surface in this case as well. Immediately to the north and south of this heating are cooling regions that also extend to great depth.

Both heating and cooling are important for determining the circulation demanded by the increase in wind stress. For equatorward-flowing water to return poleward, the heating on the equatorward limb must be countered by cooling. To the extent that this cooling can occur locally, a local cell is possible; to the extent that the local cooling is insufficient, a basinwide cell may be necessary. In the SH-Westerlies case, the basinwide cell is only about one-third as strong as the Ekman transport. As Fig. 4c shows, much of the remaining volume transport returns in a local cell that features cooling between about $30^{\circ}$ and $40^{\circ} \mathrm{S}$ in the $8^{\circ}-12^{\circ} \mathrm{C}$ temperature range, which corresponds to depths of about $100-550 \mathrm{~m}$ in No-Wind and 200-750 $\mathrm{m}$ in SH-Westerlies. What process produces this cooling?

We look at the individual terms on the right-hand side of (2). Surface heating is associated with convection and vertical diffusion (Fig. 6), while convection cools a region that is generally shallower and farther poleward than the cooling that we are looking for. In the experiments discussed above, it is the horizontal diffusion term that is responsible for deeper cooling between $30^{\circ}$ and $40^{\circ} \mathrm{S}$, as well as some warming farther poleward (Figs. 6b,c). This is consistent with horizontal diffusion acting to permit more local recirculation (Gnanadesikan $1999)$. For the Lo- $\kappa_{H}$ runs, local cooling is due to vertical diffusion instead (Figs. 6e,f), but in either case the amount of local cooling is the same. These results suggest that the relative strengths of the local and basinwide cells are not set by the diffusivity parameters and that to some extent the temperature distribution adjusts to produce the required subsurface heating and cooling.

\section{d. Potential energy creation by mixing}

TsuSu assert that the increase in overturning associated with the wind is due to the wind increasing the 
(a)

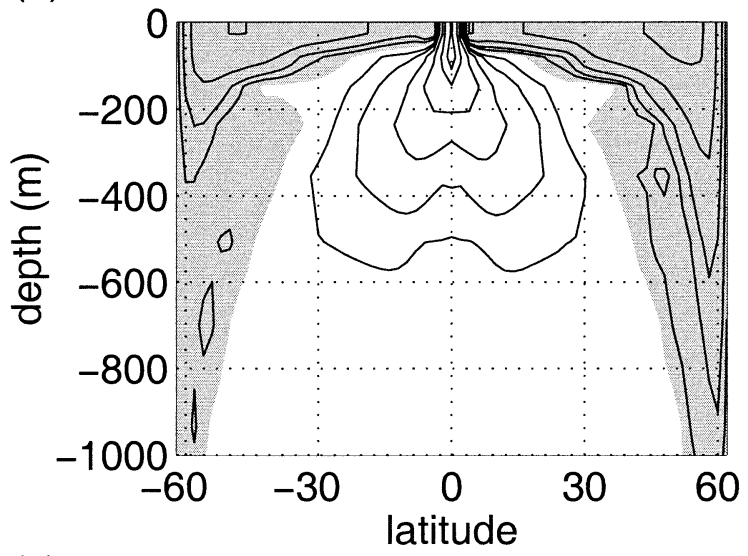

(c)

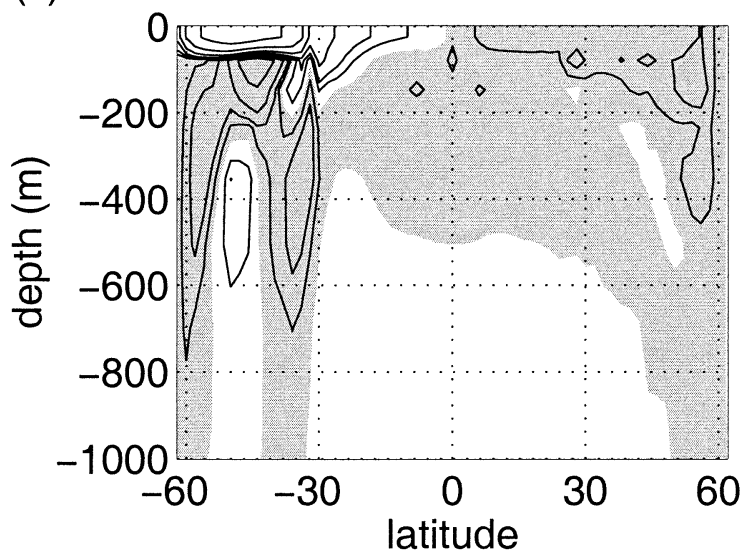

(b)

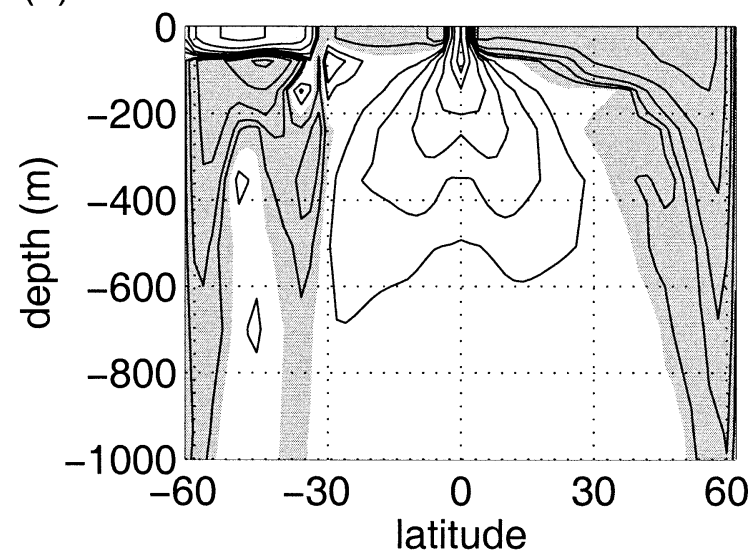

(d)

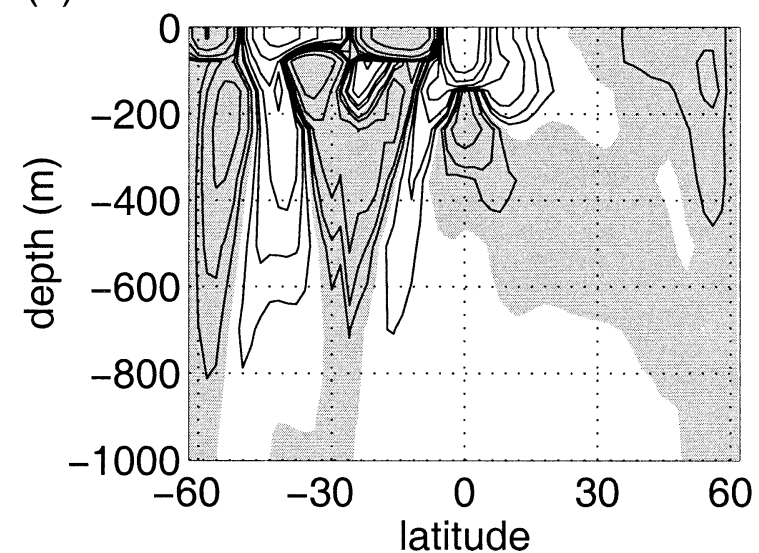

FIG. 5. Zonal average of $\boldsymbol{\nabla} \cdot(\mathbf{u} T$ ) for exp (a) No-Wind, (b) SH-Westerlies, (c) SH-Westerlies minus No-Wind, and (d) Full-Wind minus NoWind. Contours are exponentially distributed at $\pm 0.1, \pm 0.2, \ldots, \pm 12.8$ in units of $10^{-8}{ }^{\circ} \mathrm{C} \mathrm{s}^{-1}$, with shaded areas representing cooling.

diapycnal diffusion and thus enhancing the thermohaline circulation. A potential energy budget can be written for the entire basin (Huang 1998, 1999). If the wind is truly driving an "enhanced thermohaline" circulation, the term associated with mixing should increase when wind is added to the system [see the discussion in Scott and Marotzke (2002)]. We test this hypothesis here.

The rate at which mixing produces potential energy in the system is given by

$$
P_{\mathrm{PE}}=g \iint \kappa_{V} \rho_{z} d z d S=\kappa_{V} g \int\left(\rho_{b}-\rho_{s}\right) d S
$$

(see Huang 1998), where $g=9.8 \mathrm{~m} \mathrm{~s}^{-2}$ is the gravitational constant, $\rho_{b}$ and $\rho_{s}$ are densities at the bottom and surface, and the outer integral is over the latitudelongitude extent of the basin. In the numerical experiments, $\left(\rho_{b}-\rho_{s}\right)$ is proportional to $T_{s}-T_{b}$. Comparing the wind-driven runs to the No-Wind run, we find that $P_{\mathrm{PE}}$ decreases by roughly $1 \%$ for the Full-Wind, SHWesterlies, and NH-Westerlies experiments. Thus even though overturning increases in all three cases, potential energy generation decreases in all three. The decrease in $P_{\mathrm{PE}}$ occurs because, in addition to diffusion increasing in places, it decreases elsewhere (Figs. 5c,d); on average the induced heating is shallower than the induced cooling.

We conduct an additional experiment that is identical to No-Wind except that south of $30^{\circ} \mathrm{S}$ and in the top $603 \mathrm{~m}, \kappa_{V}$ is multiplied by a factor of 10 . In that case, $P_{\mathrm{PE}}$ is 2.55 times bigger than in the No-Wind case. All of these $P_{\mathrm{PE}}$ results indicate that the wind is not increasing the overturning by enhancing thermohaline (i.e., mixing) processes, but is acting through a mechanism characterized by a different kind of perturbation to the energy budget.

\section{Why westerlies generate net local heating}

Here we analyze the temperature evolution equation to show that it is plausible that high-latitude westerlies must produce local positive surface heat flux, which must be balanced by surface cooling elsewhere. Using Cartesian coordinates for simplicity, the zonal average temperature equation in a closed basin is

$$
v T_{y}+w T_{z}=\kappa_{V} T_{z z}+C,
$$

where all quantities refer to zonal averages and where 
(a)

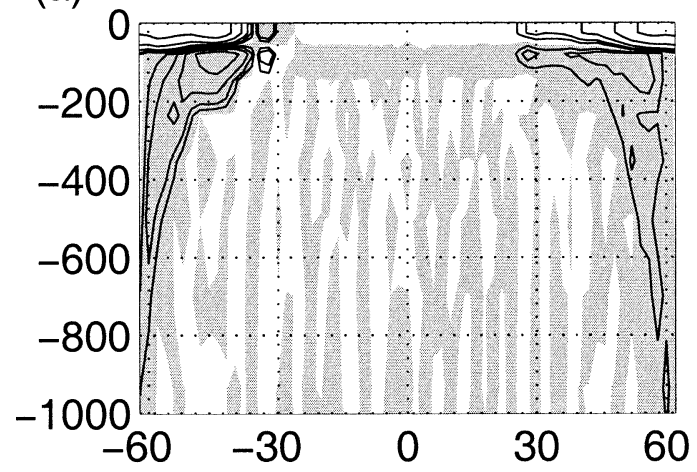

(b)

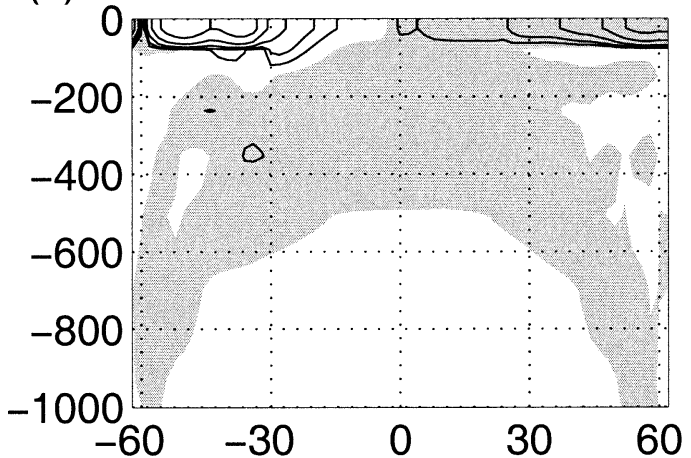

(c)

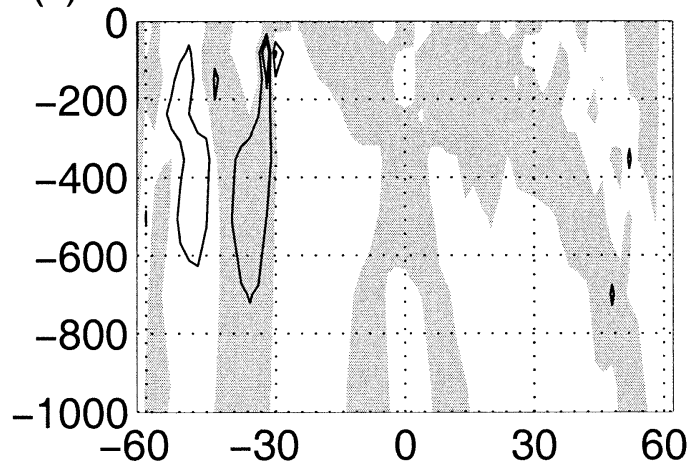

(d)

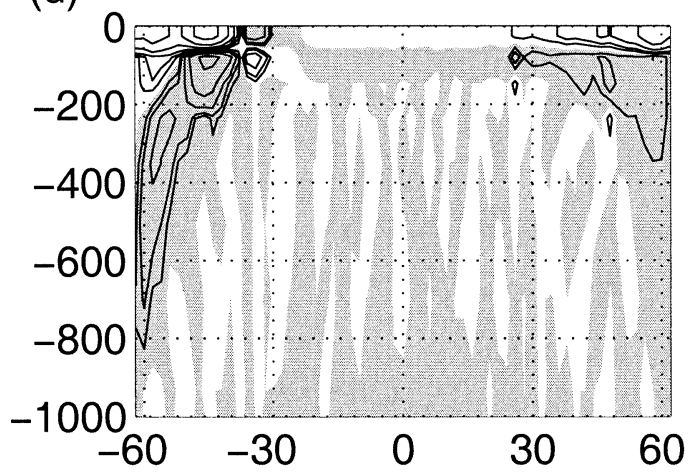

(e)

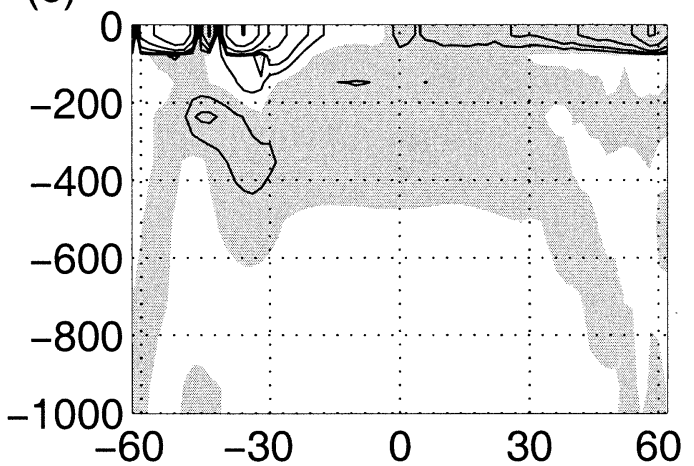

(f)

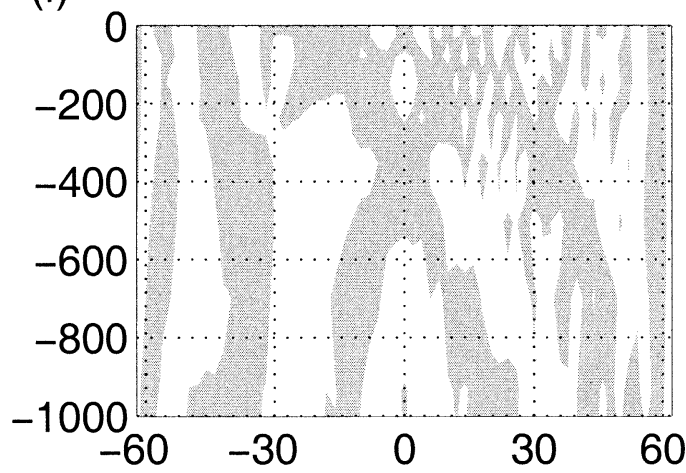

FIG. 6. Zonal averages of (top) convection, (center) vertical diffusion, and (bottom) horizontal diffusion terms from (2), showing difference (left) between SH-Westerlies and No-Wind experiments and (right) between Lo- $\kappa_{H} /$ Westerlies and Lo- $\kappa_{H} / \mathrm{No}$-Wind experiments. Contours are as in previous figure.

we have assumed that we can neglect horizontal diffusion terms and that the average of products is equal to the products of averages $(\langle v T\rangle=\langle v\rangle\langle T\rangle$, etc.). The surface heat flux $Q$ only appears when we take the vertical integral of (4), which yields

$$
R=\int_{-H}^{0}\left(v T_{y}+w T_{z}\right) d z+\kappa_{V} T_{z H}-\int_{-H}^{0} C d z,
$$

where $R=\kappa_{V} T_{z}=Q /\left(c_{p} \rho\right), c_{p}$ is specific heat, subscript $H$ represents evaluation at $z=-H$, and $H$ is a typical Ekman layer depth.

The terms on the right-hand side of (5) represent both heating and cooling. We will show that when a westerly wind perturbation is applied to the southern hemisphere, it is difficult for the cooling terms to become as large as the heating terms in the latitude band of the wind perturbation, and so heating must dominate. Here we represent each SH-Westerlies quantity as being the sum of a No-Wind and perturbation value; for instance $R=$ $\bar{R}+R^{\prime}$.

An equation for $R^{\prime}$ can be derived by subtracting the equations for $\bar{R}$ from $R$, and simplified as follows. We assume that the wind is strong enough for the Ekman speeds to be at least as large as the No-Wind speeds (as in the numerical experiments) so that perturbation velocities are not negligible when compared with No-Wind velocities. Because the near-surface temperature is strongly 
constrained by surface forcing, the perturbation temperatures are negligible in comparison with the No-Wind state. Therefore the perturbation form of (5) is approximately

$$
R=\int_{-H}^{0}\left(v^{\prime} \bar{T}_{y}+w^{\prime} \bar{T}_{z}\right) d z+\kappa T_{H z}^{\prime}-\int_{-H}^{0} C d z .
$$

For westerly winds in the southern hemisphere, $v^{\prime}>$ 0 and $\bar{T}_{y}>0$, and so the horizontal advection term represents heating. The vertical advection term represents heating in the south (Ekman upwelling) and cooling in the north (Ekman downwelling). Is this cooling much smaller than the heating? If $v^{\prime}$ and $w^{\prime}$ are both due to Ekman transport, continuity demands that $v^{\prime} H$ $\sim w^{\prime} L$, where $L$ is the meridional extent of the downwelling region. However, because the thermocline is much deeper than the Ekman layer, $\bar{T}_{y} L \gg \bar{T}_{z} H$. Combining these two relations, we find that the vertical advection term must be much weaker than the horizontal advection term.

We would also expect the diffusion term in (6) to be negative. If the thermocline has a characteristic thickness $D$ and temperature range $\Delta T$, the ratio of the terms is roughly approximated by

$$
\frac{\kappa_{V} T_{z H}^{\prime}}{\int v^{\prime} \bar{T}_{y} d z} \sim \frac{\kappa_{V} \Delta T(1 / \bar{D}-1 / D)}{H V_{\mathrm{Ek}} \Delta T / L} \approx \frac{\kappa_{V} / \bar{D}}{H V_{\mathrm{Ek}} / L} \frac{D^{\prime}}{\bar{D}},
$$

where $H V_{\mathrm{Ek}}$ is the Ekman transport. One can show that it is plausible that $D^{\prime} / \bar{D} \ll 1$, while the other fraction is $O(1)$, so the diffusion term should be smaller than the horizontal advection term. We cannot explicitly estimate the strength of the convection term, but this is also likely to be small.

To summarize, we analyzed the temperature evolution equation in a surface layer to see if there is any constraint that forces the surface heat flux anomaly to be predominantly positive in the region of westerly winds. A surface heating anomaly is associated with the horizontal advection term, as northward Ekman transport warms the surface water. We show that for Ekman upwelling at least as large as thermohaline upwelling, this term dominates the vertical advection and diffusion terms. The positive heat flux must be balanced by negative heat flux elsewhere, which is produced via a basinscale overturning anomaly.

It is interesting to consider some of the assumptions used here. One is that the perturbation flow in the Ekman layer is dominated by the Ekman velocity. Ekman transport is associated with a geostrophic return flow, which we have assumed is small in the Ekman layer because it is extends down to the base of the thermocline. If the return flow could all occur in the Ekman layer, a balance between local cooling and heating would be possible. Another assumption is that temperature perturbations are small. Rahmstorf and England (1997) have discussed how weaker restoring of the surface temperature makes the overturning less sensitive to the "Drake Passage Effect" in a global model. Weaker restoring can affect our heat budget discussion in two ways. First, the temperature perturbations become larger and may not be as negligible. In addition, the larger temperature perturbations can induce a change in the thermohaline circulation (as Rahmstorf and England discuss) that counters the wind-induced cell.

\section{Discussion and conclusions}

In a series of numerical experiments, we have shown that a number of parameters can significantly alter the basinwide influence of the wind on the meridional overturning. The presence of a region of subpolar zonal periodicity (the Southern Ocean) was originally invoked as a key factor in allowing the wind to drive such largescale overturning (Toggweiler and Samuels 1995), but the fact that a strong overturning can be driven in the absence of such periodicity (Tsujino and Suginohara 1999) casts some doubt on this explanation. Our experiments confirm that such a basinwide circulation is indeed a robust feature even in a closed basin, but that the presence of a zonally periodic channel boosts the strength of the overturning anomaly by about a factor of 2, as measured by cross-equatorial volume transport. This confirms the picture suggested by Klinger et al. (2002). Further experiments elaborate on some of the other parameters that control the sensitivity of the overturning to wind stress.

TsuSu's basin is rather short in the meridional direction so that the peak westerlies are at about $25^{\circ}$ latitude (in contrast to a real-world peak near $40^{\circ}$ ); this factor alone doubles the overturning anomaly, because of a roughly $50 \%$ increase in Ekman transport associated with the smaller Coriolis parameter at lower latitudes. When we simply double the wind stress amplitude, the cross-equatorial volume transport anomaly more than doubles, confirming that the large-scale overturning strength is not strictly proportional to Ekman transport.

More subtle features of the forcing are also important. For instance, changing the surface density contrast between the northern and southern boundary of the basin has a significant effect on the deep flow anomaly at virtually all latitudes. For westerly wind forcing, the induced overturning is shallower when the wind stress is imposed on the "dominant" hemisphere of deep-water formation rather than the "subordinate" opposite hemisphere.

One parameter that does not strongly influence the sensitivity to wind is horizontal diffusivity $\kappa_{H}$. A factor of 10 decrease in $\kappa_{H}$ slightly decreased the basinwide overturning. This is in sharp contrast to the behavior in a basin with a Southern Ocean. As in the Southern Ocean case, the sensitivity to the wind is qualitatively the same when horizontal diffusion is replaced by isopycnal/Gent-McWilliams diffusion, which is thought to better represent the real ocean. In all experiments, 
the shallow meridional volume transport anomaly $\Phi$ directly under the wind stress forcing is proportional to the Ekman transport; $\Phi_{T}$, the shallow volume transport anomaly as a function of temperature, is somewhat less closely linked to Ekman transport, while the cross-equatorial transport anomaly shows, in most cases, similar sensitivity whether calculated as a function of depth or temperature.

We do not have a theory that can even approximately predict the strength or depth of the large-scale overturning due to the winds in a closed basin. TsuSu argue that the overturning is due to enhanced diffusive heating in the wind-driven region. We show here that the winddriven heating can occur at depth, where it is associated with diffusion, or at the surface, where it is associated with the surface heating of equatorward Ekman transport. Generally speaking, the largest heating occurs near the surface, and the fraction of heating occurring at depth increases when the water in the Ekman upwelling is more stratified. There is also subsurface cooling below the region of wind stress forcing, which allows some of the surface Ekman transport to return locally rather than taking a basinwide path. Changing the horizontal diffusivity strongly affects the relative importance of horizontal and vertical diffusion in producing this cooling, even though it hardly affects the combined cooling. Tsujino and Suginohara argue that wind stress increases the thermohaline circulation by increasing diffusion. When overturning is strengthened by the addition of wind stress, $P_{\mathrm{PE}}$, the potential energy generation due to diffusion, decreases slightly. This implies that the average depth of heating is slightly shallower than the average depth of cooling. Since $P_{\mathrm{PE}}$ is a measure of the strength of the thermohaline circulation, our $P_{\mathrm{PE}}$ result suggests that wind enhancement of overturning operates through a different mechanism than simply increasing diffusion. The wind-driven overturning is broadly thermohaline in the sense that heating and cooling are important aspects of the circulation, but it is not thermohaline in the more narrow definition of a system in which mixing powers the motion.

Hasumi and Suginohara (1999) argue that the remote wind-driven overturning follows from the induced surface heat flux, which has local heating and remote cooling. We strengthen this argument by showing why the wind induces the heat flux observed in experiments: scale analysis indicates that local overturning will produce local heating that cannot be balanced by local cooling. In a way, this reasoning is a generalization of Toggweiler and Samuels's original explanation. Even when there is no Drake Passage, the geostrophic return flow is distributed over a depth range comparable to the thermocline thickness, which is greater than the Ekman layer thickness. A purely local overturning anomaly still implies greater water mass transformation than the dynamics can accommodate.

The presence of a zonally periodic channel puts strong constraints on the dynamics, which leads to a scaling for overturning strengths that is broadly consistent with numerical results (Gnanadesikan 1999; KDMS). For a closed basin, meridional geostrophic flow is part of a three-dimensional gyre circulation that apparently allows much, but not all, of the Ekman transport to cool and return locally. How much of the Ekman transport should take the local route and how much should take the basinwide path? Current understanding of the threedimensional wind-driven circulation, starting with Luyten et al. (1983), is largely based on adiabatic theory that excludes the western boundary current, which implies no deep cooling and hence no local overturning except for some near-surface flow associated with the warm western boundary current. Scale relations have been applied with some success to explain the dependence of the thermohaline circulation on vertical mixing (e.g., Bryan 1987). However, the extension to include both wind stress and diffusive effects is difficult. Moreover, the scaling of the meridional overturning with other parameters, such as the meridional density gradient, has proven less successful (Scott 2000). The incorporation of explicit thermal wind balance of the meridional overturning into the advective-diffusive picture (Marotzke 1997; Marotzke and Klinger 2000) appears as the logical starting point for an attempt to combine winddriven and buoyancy-driven dynamics but will be left for future study. One intriguing puzzle that a successful theory should explain is why the overturning anomaly is relatively insensitive to large changes in the relative importance of vertical and horizontal diffusion in the local cooling.

Acknowledgments. Barry Klinger was supported by NSF Grants OCE-9730554 at NSU and OCE-0196117 at GMU. The authors benefited from a stimulating correspondence with Nobuo Suginohara concerning fundamental physical issues and from the comments of an anonymous reviewer.

\section{REFERENCES}

Bryan, F., 1987: Parameter sensitivity of primitive equation ocean general circulation models. J. Phys. Oceanogr., 17, 970-985.

Bryan, K., 1984: Accelerating the convergence to equilibrium of ocean-climate models. J. Phys. Oceanogr., 14, 666-673.

Cox, M. D., 1989: An idealized model of the World Ocean. Part I: The global-scale water masses. J. Phys. Oceanogr., 19, 17301752 .

Döös, K., and D. J. Webb, 1994: The Deacon cell and the other meridional cells in the Southern Ocean. J. Phys. Oceanogr., 24, 429-442.

Gent, P. R., and J. C. McWilliams, 1990: Isopycnal mixing in ocean circulation models. J. Phys. Oceanogr., 20, 150-155.

Gnanadesikan, A., 1999: A simple predictive model for the structure of the oceanic pycnocline. Science, 283, 2077-2079.

Hasumi, H., and N. Suginohara, 1999: Atlantic deep circulation controlled by heating in the Southern Ocean. Geophys. Res. Lett., 26, 1873-1876.

Huang, R. X., 1998: Mixing and available potential energy in a Boussinesq ocean. J. Phys. Oceanogr., 28, 669-678. 
_ 1999: Mixing and energetics of the oceanic thermohaline circulation. J. Phys. Oceanogr., 29, 727-746.

Klinger, B., 2000: Acceleration of general circulation model convergence by exponential extrapolation. Ocean Modell., 2, 6172.

— , and J. Marotzke, 1999: Behavior of double-hemisphere thermohaline flows in a single basin. J. Phys. Oceanogr., 29, 382399.

- , and -2000 : Meridional heat transport by the subtropical cell. J. Phys. Oceanogr., 30, 696-705.

— S. Drijfhout, J. Marotzke, and J. R. Scott, 2003: Sensitivity of basinwide meridional overturning to diapycnal diffusion and remote wind forcing in an idealized Atlantic-Southern Ocean geometry. J. Phys. Oceanogr., 33, 249-266.

Luyten, J., J. Pedlosky, and H. Stommel, 1983: The ventilated thermocline. J. Phys. Oceanogr., 13, 292-309.

Marotzke, J., 1997: Boundary mixing and the dynamics of threedimensional thermohaline circulations. J. Phys. Oceanogr., 27, 1713-1728.

— metric thermohaline circulations. J. Phys. Oceanogr., 30, 955970 .

Nof, D., 2000: Does the wind control the import and export of the South Atlantic? J. Phys. Oceanogr., 30, 2650-2667.

- 2002: Is there a meridional overturning cell in the Pacific and Indian Oceans? J. Phys. Oceanogr., 32, 1947-1959.
Pacanowski, R. C., 1996: MOM 2 version 2.0 (beta) documentation user's guide and reference manual. GFDL Ocean Tech. Rep. 3.2, $329 \mathrm{pp}$.

Rahmstorf, S., and M. H. England, 1997: Influence of Southern Hemisphere winds on North Atlantic Deep Water flow. J. Phys. Oceanogr., 27, 2040-2054.

Sandström, J. W., 1908: Dynamische Versuche mit Meerwasser. Ann. Hydrogr. Marit. Meteor., 36, 6-36.

Scott, J. R., 2000: The roles of mixing, geothermal heating, and surface buoyancy forcing in ocean meridional overturning dynamics. Ph.D. thesis, Massachusetts Institute of Technology, 128 pp.

_ , and J. Marotzke, 2002: The location of diapycnal mixing and the meridional overturning circulation. J. Phys. Oceanogr., 32, $3578-3595$.

Toggweiler, J. R., and B. Samuels, 1995: Effect of Drake Passage on the global thermohaline circulation. Deep-Sea Res., 42, 477500 .

$\ldots$, and _ 1998: On the ocean's large-scale circulation near the limit of no vertical mixing. J. Phys. Oceanogr., 28, 1832-1852.

Tsujino, H., and N. Suginohara, 1999: Thermohaline circulation enhanced by wind forcing. J. Phys. Oceanogr., 29, 1506-1516.

Vallis, G. K., 2000: Large-scale circulation and production of stratification: Effects of wind, geometry, and diffusion. J. Phys. Oceanogr., 30, 933-954. 